\section{Harness passion of private fossil owners}

Reproducing palaeontological results depends on unrestricted access to fossils described in the literature, allowing others to re-examine or reinterpret them. Museums have policies and protocols for keeping materials in the public trust, but accessibility to privately owned fossil collections can be a problem.

For example, the existence of an important early bat fossil in a private collection was long known, but it was only after a second specimen was acquired and made available by a museum that researchers published a description of it (N. B. Simmons et al. Nature 451, 818-821; 2008). Another example is the unique fossil of a supposed four-legged 'snake', also privately owned, that was made temporarily available through a private German museum and then withdrawn after its description was published (D. M. Martill et al. Science 349, 416-419; 2015).

We suggest that the enthusiasm of private collectors for their valuable and spectacular fossils should instead be harnessed by researchers, to the benefit of both parties. For example, scientists can invite collectors to participate in their projects and be co-authors on the publications (R. R. Reisz et al. Sci. Nat. 102, $50 ; 2015)$, or they can name the new species after the collector (S. P. Modesto et al. Proc. R. Soc. B 282, 20141912; 2015) - all on the condition that the specimen is donated to an institution with public right of access.

Robert R. Reisz University of Toronto Mississauga, Canada. Michael W. Caldwell University of Alberta, Edmonton, Canada. robert.reisz@utoronto.ca

\section{Species can be named from photos}

As an international group of taxonomists who study a range of taxa, we consider that you misconstrued the case of a new insect species that was described on the basis of photographs (see Nature 535, 323-324; 2016).

The species was described without a preserved type specimen, the individuals having escaped before preservation (S. A. Marshall and N. L. Evenhuis ZooKeys 525, 117-127; 2015). The International Code of Zoological Nomenclature allows for this - the authors (included here as signatories) followed the letter and the spirit of the Code, giving a description and a formal species name. It was based on material that supported their conclusions and an explanation of the circumstances to justify naming a species without an extant type. Peer reviewers judged the data sufficiently reliable to anchor a species name.

As you point out, a physical specimen has features that might not be captured in a photo.

However, types are name-bearers, not "standards for species delimitation" (D. S. Amorim et al. Zootaxa 4137, 121-128; 2016). Significant knowledge about a species may build up before we can properly preserve a namebearing type. The Code allows for the naming of those species.

More than $90 \%$ of the planetary biota still awaits description. We need to adopt new technologies while recognizing that museum specimens and nomenclatural stability are crucial for taxonomy. Thomas Pape ${ }^{\star}$ Natural History Museum of Denmark, Copenhagen. tpape@snm.ku.dk

${ }^{\star}$ Supported by 34 signatories (see go.nature.com/2cur7a6 for full list).

\section{China's sponge cities} to soak up rainwater

China's Sponge City programme aims to improve resilience to urban expansion and climate change by enabling cities to save and resupply rainwater. It is crucial for cities such as Beijing and Jinan, which suffer water shortages even after severe flooding. However, several hurdles must be overcome to get it working efficiently.

The programme will involve some 30 pilot cities this year (see www.mohurd.gov.cn). They will create a 'sponge' infrastructure to detain runoff, control flooding, recharge groundwater and reuse storm water. The project still has to recruit enough planners, designers and construction workers to support this colossal initiative. Time is short for completing technical training.

Plans and technology will need to be customized for individual cities, where local weather conditions and the degree of urbanization can vary considerably; a blanket strategy will not work.

Once in place, the sponge infrastructure should be combined with conventional drainage systems, particularly in areas of medium- and highintensity urbanization.

Dasheng Liu Ecological Society of Shandong, Jinan; and Ludong University, Yantai, China. liu_sdiep@126.com

\section{Clearing the way for reef destruction}

Agricultural practices are accelerating the health decline of Australia’s Great Barrier Reef, affecting marine and terrestrial ecosystems (see also S. L. Maxwell et al. Nature 536, 143-145;

2016). Last month, intensive opposition from the agricultural lobby blocked new legislation by the Queensland government that would have protected the reef's catchment areas from land clearing - despite support for the legislation from almost 500 scientists (go.nature. com $/ 2 \mathrm{cnlftg}$ ).

Broadscale land clearing tripled after the state relaxed its vegetation regulations in 2013 (see go.nature.com/2cjn6zm). Subsequent assurances by the state that it would reduce land clearing contributed to last year's decision by the United Nations Educational, Scientific and
Cultural Organization not to add the Great Barrier Reef to its 'World Heritage In Danger' list.

The new regulations would have protected the pristine woodlands of Cape York and reduced terrestrial runoff, promoting recovery of those parts of the Great Barrier Reef that have been severely affected by unprecedented coral bleaching.

Preserving what remains of the reef's world-renowned biodiversity depends on urgently forging effective agreements with Queensland's agricultural sector. April E. Reside University of Queensland, Brisbane, Australia. Tom C. L. Bridge, Jodie L. Rummer James Cook University, Townsville, Queensland, Australia. a.reside@uq.edu.au

\section{Avoid bias against junior researchers}

I disagree with Joy BurroughBoenisch's proposal that journal reviewers and editors, as well as English-language editors, should be informed when papers are to be assessed as part of a higher degree (Nature 536, 274; 2016).

The (student) status of an author is irrelevant to whether the science is of sufficient quality to justify publication. A declaration of student status could entrench bias against junior scientists who already have few, if any, publications on which to build a reputation.

I also question whether service providers who assist in the publication process warrant listing in a $\mathrm{PhD}$ thesis statement. Editors, for example, improve the quality of the science through appropriate peer review and - along with copy editors and English-language editors for translated texts optimize its presentation through clarification and technical correction. However, they are not part of the scientific advance that justifies publishing the paper in the first place.

Andrew K. Skidmore University of Twente, the Netherlands. a.k.skidmore@utwente.nl 